\title{
Recurrences and Ongoing Complaints of Diverticulitis; Results of a Survey among Gastroenterologists and Surgeons
}

\author{
M.A.W.Stam W.A. Draaisma E.C.J.Consten I.A.M.J. Broeders \\ Department of Surgery, Meander Medical Centre, Amersfoort, The Netherlands
}

\section{Key Words}

Diverticulitis · Survey · Recurrence · Ongoing complaints ·

Sigmoid resection

\begin{abstract}
Objective: This study aims to investigate the current opinion of gastroenterologists and surgeons on treatment strategies for patients, with recurrences or ongoing complaints of diverticulitis. Background: Treatment of recurrences and ongoing complaints remains a point of debate. No randomized trials have been published yet and guidelines are not uniform in their advice. Design: A web-based survey was conducted among gastroenterologists and GE-surgeons. Questions were aimed at the treatment options for recurrent diverticulitis and ongoing complaints. Results: In total, 123 surveys were filled out. The number of patients with recurrent or ongoing diverticulitis who were seen at the outpatient clinic each year was $7(0-30)$ and $5(0-115)$ respectively. Surgeons see significantly more patients on an annual basis 20 vs. $15 \%(p=0.00)$. Both surgeons and gastroenterologists preferred to treat patients in a conservative manner using pain medication and lifestyle advise (64.4 vs. $54.0, p=0.27$ ); however, gastroenterologists would treat patients with mesalazine medication, which is significantly more $(28 \%, p=$ $0.04)$ than in the surgical group. Surgeons are inclined more towards surgery $(31.5 \%, p=0.02)$. Conclusions: Both surgeons and gastroenterologists prefer to treat recurrent di-
\end{abstract}

verticulitis and ongoing complaints in a conservative manner. Quality of life, the risk of complications and the viewpoint of the patient are considered important factors in the decision to resect the affected colon.

(C) 2016 The Author(s)

Published by S. Karger AG, Basel

\section{Introduction}

Treatment of recurrences and ongoing complaints has been a point of debate ever since Janes proved that the severity of recurrences does not progress with every episode. Ever since, several investigators have tried to answer this question. However, no randomized trials have been published yet. This is surprising considering the extent of this health care problem, since $33 \%$ of patients continued to experience complaints after an episode of uncomplicated diverticulitis. Another 33\% experienced recurrent episodes of diverticulitis [1-9].

Consequently, current guidelines are not uniform in their suggestions [10-15]. In 2000, the standard task force of the American Society of Colon and Rectal surgeons recommended that a sigmoidectomy be performed after a second episode of diverticulitis [10]. Subsequently, the rate of sigmoidectomies increased [2]. In 2006, these guidelines were updated to a more tailor-made approach in concordance with the guidelines from the Association of Coloproctology of Great Britain and Ireland [15]. This

\begin{tabular}{ll}
\hline KARGER & $\begin{array}{l}\text { ( } 2016 \text { The Author(s) } \\
\text { Published by S. Karger AG, Basel } \\
\text { 0253-4886/16/0333-0197\$39.50/0 }\end{array}$ \\
E-Mail karger@karger.com & This article is licensed under the Creative Commons Attribution- \\
www.karger.com/dsu & $\begin{array}{l}\text { NonCommercial-NoDerivatives 4.0 International License (CC BY- } \\
\text { NC-ND) (http://www.karger.com/Services/OpenAccessLicense). } \\
\text { Usage and distribution for commercial purposes as well as any dis- } \\
\text { tribution of modified material requires written permission. }\end{array}$
\end{tabular}

M.A.W. Stam

Department of Surgery

Meander Medical Centre, PO Box 1502

NL-3800 BM Amersfoort (The Netherlands)

E-Mail m.gorter@vumc.nl 
Table 1. Baseline

\begin{tabular}{|c|c|c|c|c|}
\hline & $\begin{array}{l}\text { All, } \\
\text { n (\%) }\end{array}$ & $\begin{array}{l}\text { Gastroenterologist, } \\
\mathrm{n}(\%)\end{array}$ & $\begin{array}{l}\text { Surgeon, } \\
\mathrm{n}(\%)\end{array}$ & $\mathrm{p}$ value \\
\hline Specialization & $123(100)$ & $50(40.7)$ & $73(59.3)$ & \\
\hline Setting & 123 & $50(100)$ & $73(100)$ & 0.84 \\
\hline Academic hospital & $21(17.1)$ & $8(16.0)$ & $13(17.8)$ & \\
\hline Teaching hospital & $77(62.6)$ & $33(66.0)$ & $44(60.3)$ & \\
\hline Peripheral hospital & $25(20.3)$ & $9(18.0)$ & $16(21.9)$ & \\
\hline Years of experience, median (range) & $10(0-30)$ & $10(0-29)$ & $10(0-30)$ & 0.40 \\
\hline Focus & $123(100)$ & $50(100)$ & $73(100)$ & \\
\hline Gastroenterology & $50(40.7)$ & $12(24.0)$ & $38(52.1)$ & \\
\hline +Oncology & $41(33.3)$ & $14(28.0)$ & $27(37.0)$ & \\
\hline +Upper GI & $25(20.3)$ & $23(46.0)$ & $2(2.7)$ & \\
\hline Oncology & $6(4.9)$ & $1(2.0)$ & $5(6.8)$ & \\
\hline Obesity & $1(0.8)$ & $0(0.0)$ & $1(1.4)$ & \\
\hline \multicolumn{5}{|l|}{ Diverticulitis patients in outpatient clinic in } \\
\hline 1 year, median (range) & $20(0-60)$ & $15(1-50)$ & $20(0-60)$ & 0.00 \\
\hline Recurrent & $7(0-30)$ & $5(1-30)$ & $20(0-60)$ & 0.32 \\
\hline Ongoing & $5(0-115)$ & $6(1-60)$ & $5(0-115)$ & 0.87 \\
\hline Ongoing complaints, weeks, median (range) & $6(1-24)$ & $4(1-12)$ & $6(91-24)$ & 0.54 \\
\hline
\end{tabular}

was, however, not based on thorough research. The Dutch guidelines advise that patient-bound factors should be taken into account when making a decision to perform sigmoidectomy in patients with ongoing complaints and recurrent disease, rather than the number of episodes alone [11]. Improvement of quality of life (QoL) and discomfort caused by abdominal symptoms may very well outweigh the procedure-related risks and, therefore, form the most compelling reason for offering elective resection [13]. Many surgeons are reluctant to perform elective resections due to the risk of procedure-related complications [2]. This study aims at investigating the current opinion of surgeons and gastroenterologists on treatment strategies for patients with recurrences or ongoing complaints of diverticulitis in order to determine the attitude towards surgery and compliance with current guidelines.

\section{Methods}

All members of the Dutch Society for Gastrointestinal Surgery (NVGIC) and Dutch society of Gastroenterologists (NVGE) were invited to fill out a web-based survey. The survey was available either through a link, in the newsletter, or through the closed content of the different member websites. After 4 weeks, an e-mail reminder was sent. Baseline characteristics on the participating specialists were collected (number of years of experience, field of experience, estimated number of patients with diverticulitis encountered yearly, type of hospital, age, sex). Residents, researchers and retired specialists were excluded. The survey consisted exclusively of questions on the treatment of recurrences and ongoing complaints of diverticulitis. Patients suffering from stenosis after a previous episode were excluded. The Hinchey classification was used as a golden standard to describe the targeted patients. Both 'Yes or No' and multiple answer questions were used. Some questions have the possibility of entering free text. Results were collected in a database.

\section{Statistical Analysis}

The questionnaires were processed using SPSS 22. Descriptive statistics were provided of all variables. Continuous data were described as means with SD or, when appropriate, median with range. For categorical variables, the counts and percentages were calculated. Responses were compared using the chi-square test and student's $t$ test. If indicated non-parametric tests were done. Statistical significance was defined as $\mathrm{p} \leq 0.05$.

\section{Results}

\section{General Results}

In total, 123 surveys were completed, representing $8.1 \%(50 / 620)$ of all members of the NVGIC and $14.0 \%$ (73/522) of all members of the NVGE. A majority of respondents are employed in a teaching hospital in the Netherlands (62.6\%). Only $17.7 \%$ works in a university hospital and $20.3 \%$ of respondents work in smaller regional hospitals.

Overall, the median experience with the treatment of patients with diverticulitis of the respondents was 10 years (range $0-30$; table 1 ). The main focus of the participants is listed in table 2. 
Table 2. Specialty

\begin{tabular}{lcc}
\hline Specialty & $\begin{array}{l}\text { Gastroenterologists, } \\
\mathrm{n}(\%)\end{array}$ & $\begin{array}{l}\text { Surgeons, } \\
\mathrm{n}(\%)\end{array}$ \\
\hline General gastroenterology & $12(24.0)$ & $38(52.1)$ \\
Oncology and general gastroenterology & $14(28.0)$ & $27(37.0)$ \\
Upper GI and general gastroenterology & $23(46.0)$ & $2(2.7)$ \\
Oncology & $1(2.0)$ & $5(6.8)$ \\
Obesity & & $1(1.4)$ \\
\hline
\end{tabular}

\section{Ongoing Complaints and Recurrences}

Definitions

The definition of recurrences varied among responders. Most responders defined recurrences as the re-appearance of symptoms of diverticulitis within different time frames. Furthermore, respondents found a median of 6 (range 1-24) weeks sufficient to justify ongoing complaints. For surgeons, this was 6 (range 1-24) weeks and for gastroenterologists this was 4 (range 1-12) weeks (NS). The estimated number of patients with recurrences and ongoing complaints in the outpatient clinic was not statistically different between both groups either $(\mathrm{p}=0.32$ and $\mathrm{p}=0.87$ respectively; table 1 ).

\section{Management of Ongoing Complaints and}

Recurrences

Both surgeons and gastroenterologists preferred to treat patients with recurrences and ongoing complaints in a conservative manner using pain medication and lifestyle advise (62.2\%). However, $28 \%$ of gastroenterologists would (also) treat patients with mesalazine medication, which is significantly more $(\mathrm{p}=0.04)$ than the surgeons. Surgeons tend more towards surgery $(\mathrm{p}=0.02)$. Both gastroenterologists and surgeons (66 and 81.7\%, respectively) indicated that the most compelling reason for surgery is QoL. Other important reasons were the number of episodes (35.2 and 50.0\%) and stenosis (16.9 and $24.0 \%)$. The most important argument for both gastroenterologists and surgeons against a resection was the risk of complications (82.2 and 95.5\%, respectively). Other arguments were that resection does not resolve symptoms and does not ameliorate the risk of recurrences and were both supported by 15.6 and $9.1 \%$, respectively (table 3 ).

\section{Change of Mind}

All respondents were aware of the current guidelines published in 2012. Half of them indicated that their opinion on the treatment of recurrent and ongoing diverticu- litis had changed (table 3 ). Regarding the approach, $40 \%$ of gastroenterologists and $43.8 \%$ of surgeons responded that they had become more conservative in their treatment. Only $4 \%$ of gastroenterologists and $16.4 \%$ of surgeons indicated that they had become more aggressive in their approach. The final decision to perform surgery was left up to patients in the greater part of gastroenterologists $(65.2 \%)$ and surgeons $(50.7 \%)$, and this was significantly more for gastroenterologists $(\mathrm{p}=0.00)$.

\section{Discussion}

The aim of this study was to investigate the current opinion of surgeons and gastroenterologists on treatment strategies for patients with recurrent or ongoing complaints of diverticulitis in order to determine the attitude towards surgery and compliance with current guidelines.

Even though the questionnaires were not filled out uniformly, gastroenterologists and surgeons mostly shared the same opinion. Surgeons were slightly more aggressive in their approach and inclined more towards surgery. The also received and saw more patients that asked for surgery. Gastroenterologists inclined more towards medical treatment (MT) with mesalazine.

Even though national and international guidelines exist and all respondents are aware of the content, the treatment of diverticulitis differs [10-15]. As guidelines are required to change current clinical practice, so is the assessment of barriers to adhere to these guidelines. In a recent study on the compliance of guidelines in pancreatitis, it is clear that despite existing evidence-based practice guidelines, the clinical compliance with recommendations is poor [16]. The reasons for this poor compliance in this case are merely speculative but could be related to the different physicians treating these patients. Therefore, we expected to find a marked difference in every field between surgeons and gastroenterologists; however, this was not the case. Treatment is becoming more and 
Table 3. Outcome

\begin{tabular}{|c|c|c|c|c|}
\hline & $\begin{array}{l}\text { All, } \\
\text { n (\%) }\end{array}$ & $\begin{array}{l}\text { Gastroenterologist, } \\
\mathrm{n}(\%)\end{array}$ & $\begin{array}{l}\text { Surgeon, } \\
\mathrm{n}(\%)\end{array}$ & $\mathrm{p}$ value \\
\hline Preferred treatment for recurrences and ongoing complaints $(n=162)^{*}$ & 123 & 50 & 73 & \\
\hline Lifestyle and pain medication & $74(60.2)$ & $27(54.0)$ & $47(64.4)$ & 0.27 \\
\hline Antibiotics & $15(12.2)$ & $7(14.0)$ & $8(11.0)$ & 0.78 \\
\hline Surgery & $29(23.6)$ & $6(12.0)$ & $23(31.5)$ & 0.02 \\
\hline Most important consideration for surgery $(n=174)^{*}$ & 121 & 50 & 71 & \\
\hline QoL & $91(75.2)$ & $33(66.0)$ & $58(81.7)$ & 0.14 \\
\hline Number of episodes & $50(41.3)$ & $25(50.0)$ & $25(35.2)$ & 0.94 \\
\hline Number of outpatient visits & $9(7.4)$ & $6(12.0)$ & $3(4.2)$ & 0.16 \\
\hline Other & $24(19.8)$ & $12(24.0)$ & $12(16.9)$ & 0.36 \\
\hline Most important argument against surgery $(n=126)^{*}$ & 111 & 45 & 66 & \\
\hline Yes & $61(50.0)$ & $20(40.0)$ & $41(56.2)$ & \\
\hline No & $61(50.0)$ & $29(58.0)$ & $32(43.8)$ & \\
\hline I have become & 123 & 50 & 73 & 0.05 \\
\hline More conservative & $52(42.3)$ & $20(40.0)$ & $32(43.8)$ & \\
\hline More invasive & $14(11.4)$ & $2(4.0)$ & $12(16.4)$ & \\
\hline Same & $57(46.3)$ & $28(56.0)$ & $29(39.7)$ & \\
\hline I have the final say on the decision to operate & 118 & 49 & 69 & 0.00 \\
\hline Yes & $41(34.8)$ & $7(14.3)$ & $34(49.3)$ & \\
\hline No & $77(65.2)$ & $42(85.7)$ & $35(50.7)$ & \\
\hline I am aware of the latest national guideline & 122 & 50 & 72 & 0.14 \\
\hline Yes & $101(82.8)$ & $38(76.0)$ & $63(87.5)$ & \\
\hline No & $21(17.2)$ & $12(24.0)$ & $9(12.5)$ & \\
\hline
\end{tabular}

* Multiple answers possible.

more a tailor-made decision [10-26]. The use of mesalazine, which is opted by the greater part of participating gastroenterologists, remains a subject of debate. Recently, 2 identical phase 3 , randomized, double-blind, placebocontrolled, multicenter trials have evaluated the efficacy of mesalazine and found that there is no benefit compared to the benefits of placebos [26, 27]. Therefore, the use of mesalazine warrants a cautious attitude. Surgery was considered the second best option. If the decision was made to perform a resection, QoL was the most compelling reason. Current literature shows that laparoscopic sigmoidectomy is effective in treating patients with recurrences and ongoing complaints [28, 29]. However, literature also shows a risk (up to 25\%) of recurrence in another part of the colon [30].
Remarkable is the fact that some patients may experience continuous pain in the left lower quadrant after surgery. This number is considerable and varies in literature from 3 to $60 \%$ [1-3]. The etiology of this phenomenon after surgery has not been clarified. Opted theories are other conditions such as an irritable bowel syndrome, adhesions, stenosis, incomplete sigmoid resection or changed sympathetic innervation [31]. In accordance with these assumptions, the reported re-operation rates are low and range between 0 and 3\% [3]. In our study, a minority of responders feared recurrences and complaints after resection.

The most compelling reason for not performing a surgery was the risk of complications after elective surgery. These risks are considerable and consist of anesthesia- 
related complications, temporary stoma, permanent sto$\mathrm{ma}$, anastomotic leakage requiring re-operation, sepsis and even death [32-34]. A 4-year multicenter database analysis was performed in 2012 including 743 patients with diverticulitis with a median follow-up of 9 years. The authors compared MT with surgical treatment. In this study, mortality rate was low $(0.13 \%)$. Therefore, they concluded that the risk of sigmoidectomy is low and absolutely no risk of diverticular disease-related death [1]. Others, however, state that the overall morbidity can be as high as $50 \%$ with a related mortality of $1-5 \%[2,3]$.

Oddly, most respondents treat a relatively low number of patients. The whereabouts of these patients are not merely speculative but could include the general practitioner or no medical attention at all. A number needed to treat in order to make a well-informed tailor-made decision has not been established; however, it has been described that surgeons need to perform at least 70 sigmoid resections for diverticulitis in order to reduce the number of complications [35]. One can imagine that, given the level of difficulty of these resections, patients might benefit from high volume care.

The Dutch Diverticular Group will publish the results of the primary endpoint of the DIRECT-trial, a randomized trial evaluating resections vs. conservative treatment in patients suffering from ongoing complaints and recurrences, shortly. Our study indicates that there is still much discussion about the optimal treatment of these patients and that there is need for a uniform scientific-based advice. Reviewing the literature on this topic reveals that there is lack of consensus on an international level as well $[2,3,10,11,15]$. The situation in the Netherlands is therefore a typical sample of the current situation. This calls for an international consensus meeting facilitating the transfer of knowledge between countries, the opportunity to discuss views and dogmas and above all the creation of a well-supported document.

This study does have several limitations that may need to be considered. First, the response rate of surgeons and gastroenterologists was fairly low. We believe that our study does capture a representative part of all referral centers treating diverticulitis, since all types of physicians treating diverticulitis and all types of hospitals are included. Furthermore, a significant portion of the members of this society comprises retired people, residents or students and so were not asked to answer the questionnaire. Therefore, the percentage of respondents that is still practicing in the field is much higher than reflected here. A second limitation is that all surveys are subject to answering bias. A third limitation, related to the nature of the study, is the form and number of questions asked. Lastly, many responders to the questionnaire defined diverticulitis recurrence simply as the reappearance of symptoms or an admission after discharge. This is not correlated to a time limit or imaging, thus creating the possibility to over and or underestimate the risk of recurrence. This reflects the confusion, which still exists in clinical practice regarding the concept of diverticulitis recurrence.

Both surgeons and gastroenterologists in the Netherlands prefer to treat recurrent diverticulitis and/or ongoing complaints in a conservative manner. QoL, the risk of complications and the viewpoint of the patient are considered important factors in the decision to resect the affected colon. Future studies should aim at aiding the decision-making process and give insight into the possible advantages and disadvantages of high volume care.

\section{Acknowledgements}

The authors thank all participating surgeons and gastroenterologists.

\section{Author Contribution}

M.A.W.S.: main researcher, data collection, statistics, writing manuscript; W.A.D., E.C.J.C. and I.A.M.J.B.: researcher, writing manuscript.

\section{Financial Statement}

There was no financial support for the work and other financial or personal connections to the work.

$\begin{aligned} & \text { References } \text { Binda GA, Amato A, Serventi A, Arezzo A: } \\ & \text { Clinical presentation and risks. Dig Dis 2012; } \\ & \text { 30:100-107. }\end{aligned}$


6 Pittet O, Kotzampassakis N, Schmidt S, Denys A, Demartines N, Calmes JM: Recurrent left colonic diverticulitis episodes: more severe than the initial diverticulitis? World J Surg 2009;33:547-552.

-7 Holmer C, Lehmann KS, Engelmann S, Gröne J, Buhr HJ, Ritz JP: Long-term outcome after conservative and surgical treatment of acute sigmoid diverticulitis. Langenbecks Arch Surg 2011;396:825-832.

8 Eglinton T, Nguyen T, Raniga S, Dixon L, Dobbs B, Frizelle FA: Patterns of recurrence in patients with acute diverticulitis. Br J Surg 2010;97:952-957.

9 Parks TG: Natural history of diverticular disease of the colon. A review of 521 cases. $\mathrm{Br}$ Med J 1969;4:639-642.

10 Rafferty J, Shellito P, Hyman NH, Buie WD; Standards Committee of American Society of Colon and Rectal Surgeons: Practice parameters for sigmoid diverticulitis. Dis Colon Rectum 2006;49:939-944.

-11 Andeweg CS, Felt-Bersma R, Verbon A, Stoker J, Boermeester M, Bleichrodt R: [Summary of the practice guideline on diverticulitis in the colon: diagnostics and treatment in specialty care]. Ned Tijdschr Geneeskd 2013; 157:A6124.

-12 Käser SA, Glauser PM, Basilicata G, Müller DA, Maurer CA: Timing of rectosigmoid resection for diverticular disease: the patient's view. Colorectal Dis 2012;14:e111-e116.

13 Pasternak I, Wiedemann N, Basilicata G, Melcher GA: Gastrointestinal quality of life after laparoscopic-assisted sigmoidectomy for diverticular disease. Int J Colorectal Dis 2012;27:781-787.

14 van de Wall BJ, Draaisma WA, Consten EC: DIRECT trial. Diverticulitis recurrences or continuing symptoms: operative versus conservative treatment. A multicenter randomised clinical trial. BMC Surg 2010;10:25.

15 Fozard JB, Armitage NC, Schofield JB, Jones OM; Association of Coloproctology of Great Britain and Ireland: ACPGBI position statement on elective resection for diverticulitis. Colorectal Dis 2011;13(suppl 3):1-11.
16 Greenberg JA, Hsu J, Bawazeer M, Marshall J, Friedrich J, Nathens A, Coburn N, Huang H, McLeod RS: Compliance with evidence-based guidelines in acute pancreatitis: an audit of practices in University of Toronto Hospitals. J Gastrointest Surg 2016;20:392-400.

17 Janes S, Meagher A, Faragher IG, Shedda S, Frizelle FA: The place of elective surgery following acute diverticulitis in young patients: when is surgery indicated? An analysis of the literature. Dis Colon Rectum 2009;52:10081016.

18 Dobbins C, Defontgalland D, Duthie G, Wattchow DA: The relationship of obesity to the complications of diverticular disease. Colorectal Dis 2006;8:37-40.

19 Ritz JP, Lehmann KS, Stroux A, Buhr HJ, Holmer C: Sigmoid diverticulitis in young patients - a more aggressive disease than in older patients? J Gastrointest Surg 2011;15:667674.

20 Broderick-Villa G, Burchette RJ, Collins JC, Abbas MA, Haigh PI: Hospitalization for acute diverticulitis does not mandate routine elective colectomy. Arch Surg 2005; 140:576581; discussion 581-583.

21 Yoo PS, Garg R, Salamone LF, Floch MH, Rosenthal R, Longo WE: Medical comorbidities predict the need for colectomy for complicated and recurrent diverticulitis. Am J Surg 2008;196:710-714.

22 Hall JF, Roberts PL, Ricciardi R, Read T, Scheirey C, Wald C, Marcello PW, Schoetz DJ: Long-term follow-up after an initial episode of diverticulitis: what are the predictors of recurrence? Dis Colon Rectum 2011;54: 283-288.

23 Tyau ES, Prystowsky JB, Joehl RJ, et al: Acute diverticulitis. A complicated problem in the immunocompromised patient. Arch Surg 1991;126:855-858; discussion 858-859.

24 Rotholtz NA, Montero M, Laporte M, Bun M, Lencinas S, Mezzadri N: Patients with less than three episodes of diverticulitis may benefit from elective laparoscopic sigmoidectomy. World J Surg 2009;33:2444-2447.

25 Janes S, Meagher A, Faragher IG, et al: The place of elective surgery following acute diverticulitis in young patients: when is surgery indicated? An analysis of the literature. Dis Colon Rectum 2009;52:1008-1016.
Raskin JB, Kamm MA, Jamal MM, et al: Mesalamine did not prevent recurrent diverticulitis in phase 3 controlled trials. Gastroenterology 2014;147:793-802.

27 Parente F, Bargiggia S, Prada A, et al: Intermittent treatment with mesalazine in the prevention of diverticulitis recurrence: a randomised multicentre pilot double-blind placebo-controlled study of 24-month duration. Int J Colorectal Dis 2013;28:1423-1431.

28 Pasternak I, Wiedemann N, Basilicata G, et al: Gastrointestinal quality of life after laparoscopic-assisted sigmoidectomy for diverticular disease. Int J Colorectal Dis 2012;27:781787.

-29 Forgione A, Leroy J, Cahill RA, Bailey C, et al: Prospective evaluation of functional outcome after laparoscopic sigmoid colectomy. Ann Surg 2009;249:218-224.

30 Ambrosetti P, Francis K, Weintraub D, et al: Functional results following elective laparoscopic sigmoidectomy after CT-proven diagnosis of acute diverticulitis evaluation of 43 patients and review of the literature. J Gastrointest Surg 2007;11:767-772.

- 31 Polese L, Vecchiato M, Frigo AC, et al: Risk factors for colorectal anastomotic stenoses and their impact on quality of life: what are the lessons to learn? Colorectal Dis 2012; 14:e124-e128.

32 Kirchhoff P, Matz D, Dincler S, et al: Predictive risk factors for intra- and postoperative complications in 526 laparoscopic sigmoid resections due to recurrent diverticulitis: a multivariate analysis. World J Surg 2011;35: 677-683.

33 De Magistris L, Azagra JS, Goergen M, et al: Laparoscopic sigmoidectomy in moderate and severe diverticulitis: analysis of shortterm outcomes in a continuous series of 121 patients. Surg Endosc 2013;27:1766-1771.

34 Anaya DA, Flum DR: Risk of emergency colectomy and colostomy in patients with diverticular disease. Arch Surg 2005;140:681-685.

- 35 Bosker R, Groen H, Hoff C, et al: Early learning effect of residents for laparoscopic sigmoid resection. J Surg Educ 2013;70:200-205. 